GA-A24487

\title{
STABILITY OF HIGH VOLTAGE MODULATORS FOR NONLINEAR LOADS
}

\author{
by \\ C.J. PAWLEY, J. TOOKER, J. PEAVY, W.P. CARY, \\ A. NEREM, D. HOYT, and J. LOHR
}




\section{DISCLAIMER}

This report was prepared as an account of work sponsored by an agency of the United States Government. Neither the United States Government nor any agency thereof, nor any of their employees, makes any warranty, express or implied, or assumes any legal liability or responsibility for the accuracy, completeness, or usefulness of any information, apparatus, product, or process disclosed, or represents that its use would not infringe privately owned rights. Reference herein to any specific commercial product, process, or service by trade name, trademark, manufacturer, or otherwise, does not necessarily constitute or imply its endorsement, recommendation, or favoring by the United States Government or any agency thereof. The views and opinions of authors expressed herein do not necessarily state or reflect those of the United States Government or any agency thereof. 


\title{
STABILITY OF HIGH VOLTAGE MODULATORS FOR NONLINEAR LOADS
}

\author{
by \\ C.J. PAWLEY, J. TOOKER, J. PEAVY, W.P. CARY, \\ A. NEREM, D. HOYT, and J. LOHR
}

This is a preprint of a paper presented at the 20th IEEE/NPSS Symposium on Fusion Engineering, San Diego, California, October 14-17, 2003 and to be published in Fusion Science and Technology.

\author{
Work supported by \\ the U.S. Department of Energy \\ under Contract No. DE-AC03-99ER54463
}

\section{GENERAL ATOMICS PROJECT 30033 MARCH 2004}




\title{
Stability of High Voltage Modulators for Nonlinear Loads
}

\author{
C.J. Pawley, J. Tooker, J.J. Peavy, W.P. Cary, A. Nerem, D. Hoyt, J. Lohr \\ General Atomics , P.O. Box 85608, San Diego, Califonia 92186-5608
}

\begin{abstract}
Gyrotrons have a nonlinear voltage - current characteristic such that the small signal or ac impedance changes as operational voltage and currents are reached. The ac impedance determines the stability of a voltage or current control system. This can become particularly challenging when several gyrotrons are connected in parallel to a single modulator. With all gyrotrons hooked to a common ground, large current loops can be generated as well as non-canceling currents in individual coaxial lines. These inequalities can provide the required feedback impulse to start an oscillation condition in the power system for the tubes.

Recent operation of two CPI $110 \mathrm{GHz}$ gyrotrons in the $\mathrm{MN}$ class from a single modulator on DIII-D has shown instability in the power system. An oscillation in the drive current occurs at various points in the ramp up and flat top portions of the $80 \mathrm{kV}$ voltage pulse with each tube drawing $40 \mathrm{~A}$ at full voltage. Efforts to stabilize these instabilities are presented along with some modeling and examination of the issues for gyrotron modulators.
\end{abstract}

\section{INTRODUCTION}

The use of gyrotrons for electron cyclotron heating of large tokomak plasmas is already well established [1], [2]. The fact that a large number of gyrotrons at current power levels may be required to provide sufficient heating for an ITER size tokomak [3] implies a large number of high voltage modulator systems. It would be desirable to parallel several gyrotrons on to each modulator, enabling a savings in the total count of high power and high voltage components. The gyrotron tubes are active loads, with their impedances changing as a function of voltage and as the mm-wave power output changes. Therefore, when several tubes are connected in parallel to one modulator, voltage or current surges could travel back and forth on the system, destabilizing the modulator and causing undesirable variations in the gyrotrons' operating point. Under these conditions, an instability in power tetrodes often used for modulation of HV systems also cause unstable oscillations in the load current.

\section{SYSTEMS ON DIII-D}

Fig. 1 shows the setup for two of the $1 \mathrm{MW} 110 \mathrm{GHz}$ gyrotrons used on DIII-D. A power tetrode (BBC CQK 2004) [4] provides a high accuracy voltage control with a fast response time $(<35 \mu \mathrm{s})$ with an output voltage of $80 \mathrm{kV}$ and a total current of $80 \mathrm{~A}$. These systems can be modulated with a square wave to allow synchronous detection of effects in the plasma.

The output from the tetrode is split by two damping circuits. Each damper connects to a high voltage coaxial cable with two leads on the inside for transmitting the filament current from the insulated filament transformer. The damping circuit is a $400 \mu \mathrm{H}$ inductor in parallel with a $36 \Omega$ resistor. The $36 \Omega$ resistor, bridging the blocking inductor, matches the cable impedance, terminating the cable at this end. By this means the two cables are isolated from each other. Each coax

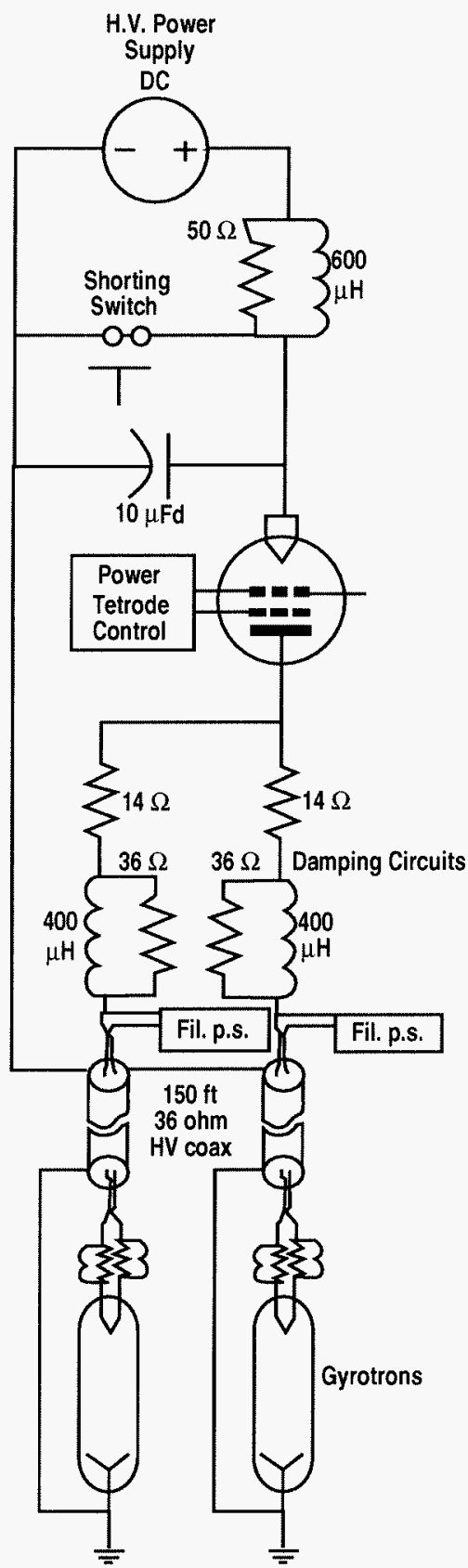

Fig. 1. The general layout for two gyrotrons being operated from a common regulator tube.

is $49 \mathrm{~m}$ long, and plugs into an oil tank interface that provides oil cooling of the cathode and insulation to the grounded tank. A snubber inductor, created by co-wound $150 \mu \mathrm{H}$ inductors and $120 \Omega$ resistors, is also in the oil to help limit current in the case of a gyrotron breakdown. The isolating inductors on the gyrotron filament are co-wound to eliminate any inductance to the filament current. The total inductance for the cathode current pulse is $150 \mu \mathrm{H}$. Each gyrotron nominally 
draws $150 \mathrm{~A}$ at $80 \mathrm{kV}$ for an output power of $1 \mathrm{MW}$ of $110 \mathrm{GHz} \mathrm{mm}$-wave power. The modulator was tested using a dummy load, a $1 \mathrm{k} \Omega$ water cooled resistor.

The outputs of the two inductors at the tetrode were connected together to one cable that connects to the dummy load. This cable is a simple coax with only one inner conductor. The modulator was able to pulse slightly over $80 \mathrm{~A}$ into the dummy load with a rise time of $1 \mathrm{~ms}$ and a stable flattop pulse several seconds long (limited by heating in the dummy load). When the modulator was connected to two gyrotrons, an instability appeared in the voltage pulse only when the current exceeded some critical value. The current through the gyrotrons is controlled by the gyrotron's cathode temperature. Increasing the gyrotron's cathode temperature increases the current through the gyrotron. When an older tetrode was in the circuit with a slightly lower emission, the system would go unstable at $65 \mathrm{~A}$ of total load current. It did not matter how much current was going through each gyrotron as long as the total reached $65 \mathrm{~A}$. A newer tetrode was installed into the modulator, resulting in 78 total amps without the instability occurring. Fig. 2(a) shows the modulator current and voltage for a stable pulse and Fig. 2(b) shows a pulse where the system has gone unstable.

The voltage pulse is programmed as a two part linear ramp. It can be seen from Fig. 2 (a) that the current has a definite change in the rate of rise during the first voltage ramp, hence doubling its small signal impedance at this point. When the shot goes unstable in the rising part of the pulse, it occurs near this point. The oscillation is detected as a fault by the
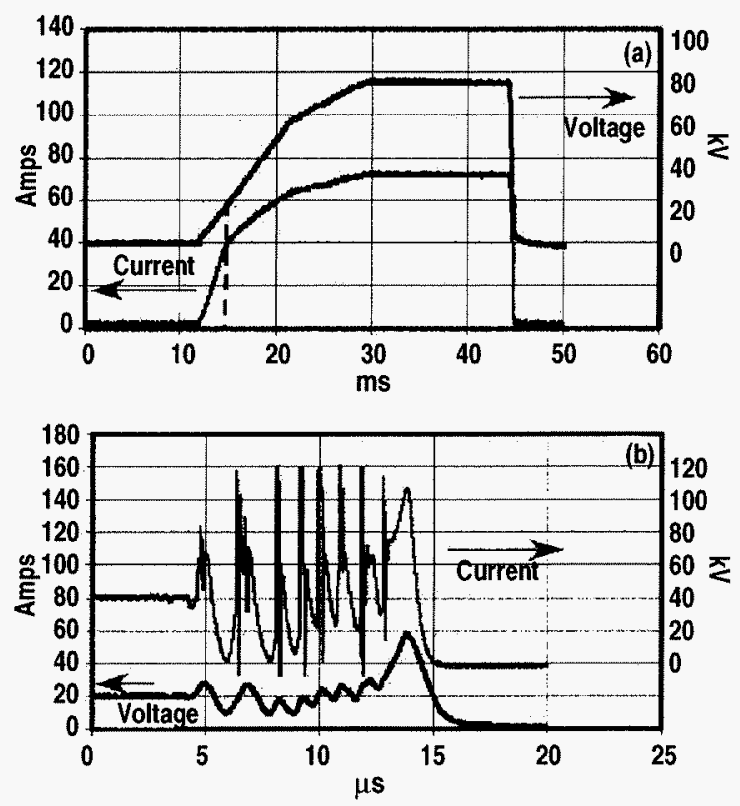

Fig. 2. (a) The top trace in this plot is the voltage trace rising to $80 \mathrm{kV}$. The lower trace is current reaching $75 \mathrm{~A}$. When the system goes unstable, the pulse ends at the dashed line. Note: the time scale is milliseconds. (b) The top trace is current and the bottom is voltage, and the time scale is microseconds. The system went unstable when the current had reached only $50 \%$ of its final value. The instability is detected by the control system and the power supply turns off approx. $100 \mu$ s later. control system, causing the modulator to shut down. The amplitude of the current oscillations is 50-60 A peak to peak and the voltage oscillations are $20 \mathrm{kV}$ peak to peak. These measurements were taken at the modulator output. A second set of measurements were taken at the gyrotron cathodes (Fig. 3). The two gyrotrons behaved nearly identically with the voltage and current in phase.

This data demonstrates that the two gyrotrons are fairly well isolated from each other by the matching resistor and inductors at the tetrode end of the cable.

The instability is not driven by currents reflecting back and forth on the two long HV coax cables.

The instability is not driven by $\mathrm{dl} / \mathrm{dt}$ on the tetrode, as we can run a single tube and shorten the rise time to less than $1 \mathrm{~ms}$ and the modulator output will remain stable. Slowing down the rise time for two gyrotrons does increase the threshold for instability, but not by much. The output rise time to two gyrotrons can be $1 \mathrm{~ms}$ for $70 \mathrm{~A}$ worth of total current, but the modulator output will not be stable with a $30 \mathrm{~ms}$ linear rise time when the current is increased to $80 \mathrm{~A}$.

The current oscillation is larger at the tetrode due to the charging and discharging of the two parallel $\mathrm{HV}$ cables. ( $13 \mathrm{nF}$ total capacitance, $\mathrm{dV} / \mathrm{dt}=20 \mathrm{kV} / 10 \mu \mathrm{s}$ which results in $26 \mathrm{~A}$ of charging current). The charging current tends to lead the voltage by $45^{\circ}$ at the tetrode (due to the inductance and resistance in the cable connection circuit), but when added to the $40 \mathrm{~A}$ in phase with the voltage due to the gyrotron current, this gives a total current of $55 \mathrm{~A}$ leading the voltage by $30^{\circ}$. This is a strong indication that the source of the instability is in the tetrode or the tetrode controller.

Tests were performed where the current was brought up very slowly until the instability begins to occur. The current begins to oscillate in the tetrode without a significant variation
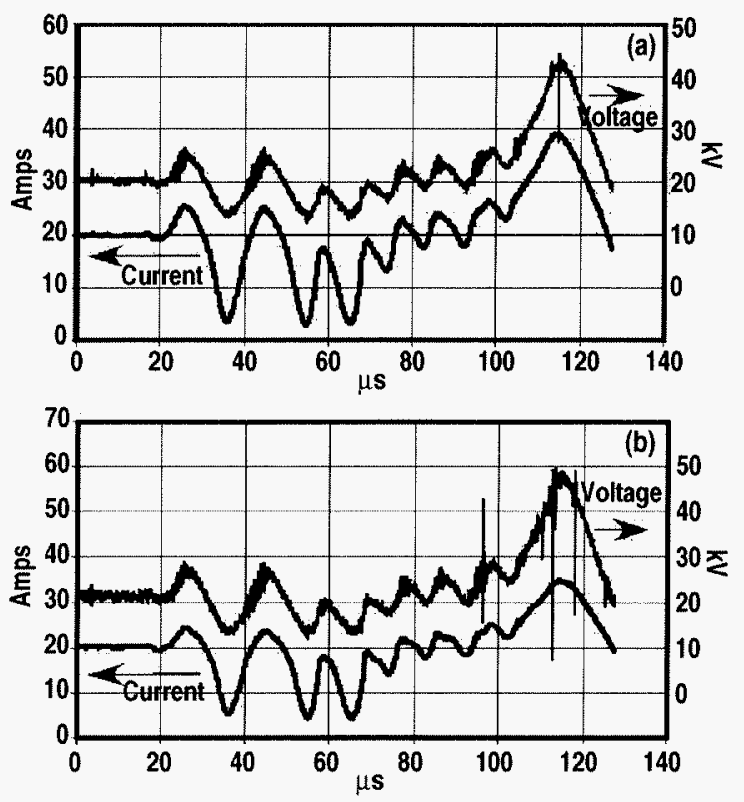

Fig. 3. (a) Current and voltage for gyrotron \#4 and (b) for gyrotron \#6. Voltage trace is on top and current is beneath. After correcting for probe calibration, they both show a $15 \mathrm{kV}$ voltage swing and a $20 \mathrm{~A}$ current swing. 
in the output voltage from the modulator. The modulator is designed to regulate the output voltage and not the current, hence a current driven instability may not be controlled. The fact that some tetrodes perform better in the circuit also points toward an instability caused by the power tetrode.

The resonance condition may be set up by the cables and inductors. The two inductors on the modulator output in combination with the two cable total capacitance gives nearly the correct ringing frequency $(100 \mathrm{kHz})$. This could occur due to the fact that grounds of the gyrotrons are common, hence some current coming down the center conductor of one cable can return on the outer conductor of the other cable, resulting in non-canceling currents in the cables. The result is the circuit behaving as though the total capacitance and inductance of the cables were two lumped components instead of a characteristic impedance of a distributed line.

Other efforts to control the oscillation have had little effect. We have tried increasing the voltage drop across the tetrode, lowering and raising the screen voltage, lowering the frequency response of the feed back loop so it would not react to the fast oscillations and effectively keep a constant control signal through the oscillations, and raising the control loop frequency response to try and control the instability. We have also tried adding $500 \mathrm{pF}$ across the tetrode (CATHODE TO PLATE) to add negative feedback to the control circuit. Several different output arrangements with the inductors and resistors as well as several physical rearrangements of the high voltage cables were tried. The effects were small shifts in the threshold or frequency of the instability.

Simulations of the system in SIMPLORER have not identified the source of the instability. The models for the gyrotron loads and the behavior of the tetrode are not complete enough to replicate the real system in simulations. Experiments in speeding up or slowing down the feedback control of the output voltage have not significantly altered the threshold for the instability. Measurements of the control grid voltage show the voltage remaining constant when the current oscillations begin. As the current excursions become larger the control reacts to suppress the output voltage oscillations. While the control signal lags the output voltage swings, it is only a 15 or $20^{\circ}$ lag at $100 \mathrm{kHz}$, insufficient to drive the instability.

\section{CONCLUSIONS}

In this paper we have identified a situation where a stable power system became unstable due to the interaction with two nonlinear loads at the ends of two long coaxial cables. The power system was tested with linear loads and showed no loss of regulation. The instability appears to be caused by the nonlinear loads creating a current instability in the power tetrode when the tetrode is operating at the upper end of its current range. The simplest way to avert this problem is to have each gyrotron controlled by its own tetrode. This is the situation for all of our remaining gyrotrons. We will later change this system to being a two tetrode control system (one for each gyrotron) mostly for the advantage in being able to independently control the voltage to each gyrotron, as each gyrotron has its own operating peak and delivers energy to a different place in the tokomak plasma. This will give the maximum experimental flexibility. In the case of ITER, it may be more economical to drive several gyrotrons from each modulator, requiring stability problems to be isolated and solved.

The problem may be eliminated by use of a single true high voltage coax line being used to transport the high voltage to the gyrotrons and placing the filament transformer at the gyrotron.

Tetrodes at high current sometimes suffer from electron transit time or electron bunching in the drift region from the extractor screen to the anode. Microwave parasitics can occur. No microwave or rf has been measured from our tetrodes, but the current instability may have a root cause in the tube at high currents. Increasing the feedback loop response may also provide stability, as we are currently limited to less than $100 \mathrm{kHz}$ due to the speed which our fiber optically coupled control system can respond. Improvements in the simulation capability with some newer control schemes may resolve this problem.

\section{ACKNOWLEDGMENT}

This work supported by the U.S. Department of Energy uncer Contact No. DE-AC03-99ER54463 and the Fusion Energy Committee.

\section{REFERENCES}

[1] T.C. Luce, Applications of high-power millimeter waves in fusion energy research, IEEE Trans. on Plasma Science, vol. 30, p 734 (2002).

[2] J. Lohr, Y.A. Gorelov, R.W. Callis, et al., Proc 12th Joint Workshop on Electron Cyclotron Emission and Electron Cyclotron Heating, G. Giruzzi, ed., World Scientific, Singapore, p 283 (2002).

[3] G. Bosia, Proc 12th Joint Workshop on Electron Cyclotron Emission and Electron Cyclotron Heating, G. Giruzzi, ed., World Scientific, Singapore, p 571 (2002).

[4] R.D. Eckard, H.W. Van Ness, D.H. Hesselgrave, Fusion Technology 1980: Proceedings of the Eleventh Symposium, 793-799 (1981). 